УДК 81'373.43-026.613

ББК 81.411.2-3

DOI: https://doi.org/10.17308/lic.2021.3/3588

\title{
ОККАЗИОНАЛЬНЫЕ ОБОЗНАЧЕНИЯ АХРОМАТИЧЕСКИХ ЦВЕТОВ В РОМАНЕ А. БЕЛОГО «МОСКВА»
}

\author{
А. В. Петров, Ю. А. Сова \\ Крымский федеральный университет имени В. И. Вернадского
}

\section{OCCASIONAL NOMINATIONS OF ACHROMATIC COLOURS IN THE ROMAN BY A. BELY "MOSCOW"}

\author{
A. V. Petrov, Yu. A. Sova \\ Crimean Federal University named after V. I. Vernadsky
}

\begin{abstract}
Аннотация: в статье на материале романа А. Белого "Москва» рассматриваются особенности словообразовательной структуры и семантики окказиональных обозначений белого и серого ахроматических ияветов. Исследование окказиональных иветообозначений как одного из основных структурирующих и семантически значимых компонентов текста вносит вклад в изучение идиостиля А. Белого. Характерной особенностью языка писателя-символиста является включение в тексты создаваемых произведений синонимических рядов и лексических единии, взятых из Словаря В. Даля. Связь между элементами текста осуществляется на основе параллельного использования окказиональных и узуальных иветонаименований, а также лексических повторов, метафоризации и ассоциативности. Группа окказиональных обозначений белого цвета в романе представлена производными, служащими для обозначения предметов одежды и частей тела персонажа, предметов интерьера, архитектурных сооружений, обобщенной иветовой характеристики описываемого пространства, пейзажа, а также ветхих предметов быта. Окказионализмы с семантикой серого ивета характеризуют пространство и предметы как подчеркнуто нечистые, зыбкие и подвергаюшиеся распаду. С опорой на «Толковый словарь живого великорусского языка» В. Даля выявлены производные единицы, соответствующие семантическому типу окказиональности. Окказиональное значение у иветообозначений проявляется в результате актуализации дифференциальной семь производящего слова. Характерной чертой идиостиля А. Белого является создание лексических окказионализмов при помощи узуальных способов словообразования с нарушением типичных сочетаемостных связей аффикса и основы.

Ключевые слова: А. Белый, роман «Москва», Словарь В. Даля, лексический и семантический окказионализм, словообразовательная структура окказионализма, хроматические и ахроматические ивета, идиостиль.
\end{abstract}

Abstract: the article examines the features of the word-formation structure and semantics of occasional designations of white and gray achromatic colours based on the novel by A. Bely "Moscow". The study of occasional colour designations as one of the main structuring and semantically significant components of the text contributes to the study of A. Belyi's idiostyle. A characteristic feature of the language of the symbolist writer is the inclusion in the texts of the created works of synonymous series and lexical units taken from the Dictionary of $V$. Dahl. The connection between the elements of the text is carried out on the basis of the parallel use of occasional and conventional color names, as well as lexical repetitions, metaphorization and associativity. The group of occasional white designations in the novel is represented by derivatives that serve to designate items of clothing and body parts of a character, interior items, architectural structures, a generalized color characteristic of the described space, landscape, as well as dilapidated household items. Occasionalisms with gray semantics characterize space and objects as emphatically impure, fragile and subject to decay. Based on the "Explanatory Dictionary of the Living Great Russian Language" by V. Dahl, derivative units corresponding to the semantic type of occasionali-

(C) Петров А. В., Сова Ю. А., 2021

Контент доступен под лицензией Creative Commons Attribution 4.0 License.

The content is available under Creative Commons Attribution 4.0 License. 
ty have been identified. Occasional meaning in color designations is manifested as a result of the actualization of the differential seme of the producing word. A characteristic feature of A. Bely's idiostyle is the creation of lexical occasionalisms with the help of conventional word-formation methods with a violation of the typical combinable connections between the affix and the stem.

Key words: A. Bely, the novel "Moscow", V. Dahl's Dictionary, lexical and semantic occasionalism, word-formation structure of occasionalism, chromatic and achromatic colours, idiostyle.

\section{Введение}

Роман «Москва» А. Белого отражает видение кризисного периода между Первой мировой войной и революцией 1917 г. в России. В последнем произведении писателя-символиста, состоящем из трех тематически связанных романов - «Московский чудак» (1926), «Москва под ударом» (1926) и «Маски» (1930), изображена панорама столицы накануне судьбоносного поворота истории: интеллигенция и профессорская Москва с подорванными моральными устоями в страхе перед грядущими изменениями.

Исследованию окказиональной лексики в прозе А. Белого с семантической и функциональной точки зрения посвящены работы Н. А. Кожевниковой, Л. А. Новикова и В. В. Селезнёвой. Некоторые лексические новообразования и часть соответствий романной дилогии «Москва» и словарных статей В. И. Даля были описаны Н. А. Кожевниковой. В ряде работ лингвист подчеркивает связь «Толкового словаря живого великорусского языка» и «Пословиц русского народа» с творчеством А. Белого. Без формулирования контекстуального значения в статьях Н. А. Кожевниковой выделены лексемы, значение которых переосмыслено писателем [1]. Исследователь отмечает характерное для романа объединение в пределах одного предложения, абзаца или соседних абзацев однокоренных окказиональных и узуальных слов, которые полностью или частично воспроизводят словарные статьи из Словаря В. Даля. Включение синонимических рядов из словарных гнезд в тексты произведений является одной из особенностей идиолекта В. И. Даля, данный художественный прием был использован А. Белым в романе «Москва».

Описанию словообразовательной структуры окказионализмов в мемуарных и некоторых прозаических произведениях А. Белого и М. Цветаевой посвящены работы А. В. Горелкиной [2]. Новообразования из романов «Москва» и «Петербург» в словообразовательном аспекте с учетом принадлежности к определенной части речи были классифицированы С. В. Кошелевой [3].

Целью предлагаемой статьи является описание словообразовательной структуры и семантики окказиональных обозначений ахроматических серого и белого цветов на материале романа А. Белого «Мо- сква». Исследованию новообразований с морфами чёрн-/черн- в романе посвящена отдельная статья [4].

В качестве основы для выделения хроматических и ахроматических цветонаименований была взята классификация Р. М. Фрумкиной, согласно которой к числу основных хроматических цветов отнесены следующие: красный, оранжевый, желтый, зеленый, голубой, синий, фиолетовый, коричневый и розовый. Основные ахроматические цвета - белый, черный и серый цвет [5].

\section{Изложение основного материала исследования}

Цветовая характеристика художественного пространства в романе «Москва», обладающая особой символикой, создается А. Белым как при помощи узуальных слов, так и с применением словотворчества в сфере цветообозначений. Новообразования, называющие ахроматические цвета, в произведениях писателя образуют триаду символов: черный цвет зло, хаос, небытие, подчеркнутая неживая природа описываемого объекта; белый цвет - символ «воплощенной полноты бытия»; серый цвет - сосуществование хаоса и гармонии, «воплощение небытия в бытие, придающее последнему [черному] призрачность» [6, с. 201]. Серый цвет выступает вторым по частотности употребления и по степени проникновения во все сферы действительности в произведении.

В романе «Москва под ударом» А. Белый изображает сцену, в которой во время празднования юбилея публикации профессором Коробкиным «Математического сборника» смущенный всеобщим вниманием Иван Иванович преодолевает путь к своему месту в зале, где его ожидают члены Математического общества. Автор использует прием метонимии, перенос характерного признака одежды, которую по случаю выбрали гости мероприятия, на самих людей: ...maким перевертышем сел рядом с ним в белоцвет из грудей, обрамленных блистально фраками [7, c. 236]. С изменением значения используется существительное «белоцвет», которое у В. И. Даля выделено в значении 'растение', у А. Белого слово представляет собой семантический окказионализм со значением 'белый фон, который образуют мужчины в белых сорочках’. В предыдущей главе автор передает высокую концентрацию белых накрахмаленных рубашек на публике при помощи метафоры «изящный 
ландшафт из крахмалов» [7, с. 236]. Форма множественного числа существительного «крахмал» усиливает акцент на большом количестве людей, собравшихся в одном зале. В структуре значения новообразования актуализируется дифференциальная сема 'белый' и теряют значимость основные семы 'порошок из пшеницы и картофеля’.

В романе «Маски» из главы в главу наблюдается тенденция к увеличению частотности употребления А. Белым окказиональных сочетаний со словом «кубовый». Новообразования с основой кубово- свидетельствуют о применении писателем кубистского принципа в изображении предметов, которые в художественном произведении приобретают нечеткие очертания, рассекаются на отдельные плоскости и кубы. Например, А. Белый создает окказионализм «кубово-белесоватый» (о хлопьях пепла из курительной трубки). Частицы пепла, представляющие собой 'легкую летучую рассыпчатую обугленную массу' [8, т. 3, с. 86], автор описывает при помощи метафоры. В значении слова «хлопья» выделены антонимичные дифференциальные семы, указывающие на компактную форму вещества: 'клочья, пушистые комья чего-нибудь' [Там же, т. 4, с. 1158], «ком» - 'кусок какого-нибудь вещества (рыхлого, мягкого, расплывшегося), уплотненный и принявший более или менее округлую форму' [Там же, т. 1, с. 1415]. Новообразование в сочетании «кубово-белесоватые хлопья» служит для характеристики рассыпающегося тускло-белого пепла из курительной трубки Киерко [7, c. 650$]$.

В романе А. Белый создает окказиональные слова со значением белого цвета для характеристики частей тела персонажей. Так, качественное прилагательное «атласно-вбеленный» является производным от узуального прилагательного «атласный» и окказионального глагола «вбелить» и служит для обозначения чего-л. гладкого, имеющего блестящую, полностью белую поверхность. Глагол «вбелить», образованный с помощью приставки в- со значением 'направления движения внутрь чего-либо’ в контексте приобретает значение 'стать абсолютно белым, насквозь белым’. В контексте «атласно-вбеленное пятно подбородка» соседствует с бакенбардами, которые охарактеризованы прилагательным «соболиные», в народно-поэтической речи традиционно служащим для обозначения не только густых и шелковистых, но и темных по цвету волос: При мысли такой... соболиные бакенбарды с атласно-вбеленным пятном подбородка (приятною ямочкой) дрогнули [7, с. 65].

Окказиональное прилагательное «белобакий», использующееся для характеристики человека по внешним признакам («два белобаких лакея»), образовано при помощи сложения основ прилагательного «белый» и существительного «баки» (просторечный вариант слова «бакенбарды») с нулевой суффиксацией $[7$, с. 420$]$. В тексте романа авторское новообразование актуализируется в значении 'имеющий белые, седые волосы, растущие от висков по щекам’.

Наречие «белоглаво» в сочетании «рыхлеть белоглаво» служит для характеристики внешности Задопятова, появившегося на вечере «Свободной Эстетики»: Задопятов... так белоглаво рыхлея и морщза свой лобик, прекнижисто выглядел [7, с. 141]. Глагол «рыхлеть» в контексте употреблен в переносном значении, характерном для просторечия: 'тучнеть, становиться дряблым'. Таким образом, сочетание «белоглаво рыхлеть» означает 'приобретать белые, седые волосы и становиться тучным'. Общий образ Задопятова описан автором при помощи окказионального сочетания «прекнижисто выглядеть». Наречие «прекнижисто», производное от прилагательного «книжный» в значении 'начитанный, ученый' [9, т. 2, с. 125], образовано при помощи префикса npe- и форманта -исто-, указывающих на высокую степень проявления признака. Окказионализм используется для выражения подчеркнутой важности в поведении персонажа, находящегося в центре внимания публики.

Для характеристики вида архитектурного сооружения автор создает окказиональное причастие «оглазуренный». Префикс о- со значением 'направление действия по окружности, вокруг предмета' актуализирует сему 'полностью', и в контексте слово приобретает значение 'полностью, по всей поверхности гладкий, глянцевый, будто покрытый глазурью (стекловидным покрытием)': Меж двух оглазуренных и белоблещущцх круглых колонн... В ряд однородных определений автор включает окказиональное качественное прилагательное «белоблещущий» со значением 'блестящий, сверкающий, сияющий белым светом' [7, с. 524].

В структуре окказионализма «сбеленный» приставка $c$ - имеет нетипичное значение 'незначительной степени интенсивности действия’. В сочетании «пальцы, сбеленные мелом» адъектив употреблен в значении 'покрытый белесым, светлым оттенком' [7, c. 152].

В пределах одного предложения Андрей Белый использует новообразования со значением цветовых оттенков: Отогнул занавеску; за окнами-мир чернодырый; дождь - кончился; брысая русость предметов нахмурилась, засеробрысилась [7, с. 340]. Окказиональное качественное прилагательное «чернодырый», образованное путем сложения основ устойчивого сочетания «черная дыра» и нулевого суффикса, употреблено в значении 'насыщенно черный; такого же цвета, как черная дыра’. В значении окказионализма «брысый», образованного при помощи усечения основы слова «белобрысый», сохраняются семы 
'очень светлый, почти белый' и нейтрализуются семы 'волосы, брови, ресницы' (Ср. белобрысый - 'с очень светлыми волосами, бровями и ресницами' [8, т. 1, c. 120]). Семантика данного новообразования построена на ассоциативности, при этом стирается исконное историческое значение корня слова: от праслав. *bry, brъve - 'бровь'. Окказиональный глагол «засеробрыситься» образован при помощи сложения основ слова «серый» с элиминированной основой прилагательного «белобрысый» и смешанного, префиксально-суффиксально-постфиксального, способа. В контексте новообразование означает процесс приобретения предметами мира темно-серого оттенка с наступлением ночи, об этом свидетельствует глагол «нахмуриться» в переносном значении 'покрываться тучами, становиться пасмурным’ [Там же, т. 4, с. 1161].

При помощи транссуффиксации (мены суффикса - $\boldsymbol{a}$ на $\boldsymbol{y}$ ) образовано с сохранением значения окказиональное наречие «добелу»: А на скверике кустики вспучились, бледные, - добелу [7, с. 215].

Окказиональное слово «замрамореть», служащее для передачи образа действия и цветовых характеристик, употреблено для описания застывших теней: Против - над домиком - вздулся белеющий облачный клок; и замраморели пятнами тени [7, с. 46]. В Словаре В. И. Даля существительное «мрамор» определяется как 'твердый и плотный камень известковой породы, белый и пестрый, идущий в поделки’ [9, т. 2, c. 355]. Поскольку тень - 'темное пространство, отгороженное, застланное чем-н. от источника света, куда не проникают лучи света' [8, т. 4, с. 680-681] - в структуре значения новообразования наблюдается нейтрализация семы 'белый’ с сохранением семантического признака 'пестрый'. Таким образом, в контексте предикат «замрамореть» используется в значении 'стать неподвижным, как камень, и приобрести пестрый узор’.

Окказиональный глагол «забелогрудиться», образованный при помощи сложения основ прилагательного «белый» и существительного «грудь», приставки за-, придающей значение 'покрыться тем, что названо производящим словом', суффикса -u-, постфикса -ся: Первая ласточка, забелогрудяся, взвизгнула: взвесилась в воздухе [7, с. 230]. В ходе контекстуального и компонентного анализа мы выделили два возможных значения у новообразования «забелогрудиться»: 1) приобрести белое оперение на груди, характерное для взрослой особи; 2) появиться на виду, стать заметным благодаря возникшему белому оперению на груди. В одном предложении автор употребляет окказиональное сочетание «взвеситься в воздухе» в значении 'повиснуть, задержаться в воздухе'.

Художественное сравнение легло в основу нетипичного окказионального сочетания «белолапое пламя» [7, с. 73]. Прилагательное «белолапый» в общем языке может быть употреблено для описания животного по цвету конечностей. Андрей Белый трансформирует устоявшуюся метафору «языки пламени», дополняя ее цветовой характеристикой и сравнивая вспышки огня по форме с лапой животного.

В тексте употреблено качественное прилагательное «серо-синявый» [7, с. 336] (мусоры розовые или серо-синявые, - гнилью извели), которое рассматривается С. В. Кошелевой [3] как окказиональное слово. Однако прилагательное «синявый» выделено в «Толковом словаре живого великорусского языка» В. И. Даля с пометой «псковское». Сложное цветонаименование использовано в сочетании с грамматическим окказионализмом «мусоры»; флексия -bl подчеркивает большое количество частиц мусора.

По аналогии с региональным словом образовано окказиональное прилагательное «серявый»: Четыре распукленьких тома: плохая бумага; обложка - серявая. Стилизация речи повествователя на уровне словообразования осуществляется при помощи суффикса -яв-, который указывает на 'неполноту, частичное проявление признака' и характерен для разговорной речи. Окказиональное прилагательное «распукленький», созданное при помощи контаминации (мены фонем «х»- «к»), употреблено без изменения в структуре значения: 'о вздутых от сырости томах книг'.

Окказиональное наименование цвета «серо-прелый» встречается в заголовке одной из подглав: $М о-$ сква - серо-прелого извета [7, с. 488]. Наблюдается расширение границ лексической сочетаемости прилагательного «прелый», которое в узусе имеет значение 'загнивающий от сырости, начавший гнить, тронутый прением' [8, т. 3, с. 740]. В тексте писателя нейтрализуется сема 'запах'.

Для обозначения пятнистого, «леопардового» цвета мебели автор создает сочетание «серо-прожухлое золото» [7, с. 745], в состав которого входит окказиональное прилагательное «серо-прожухлый» и существительное «золото» в переносном значении 'шелковая нить, сплошь обвитая тончайшею битью, позолоченною и сплющенною серебряною проволочкой’ [9, т. 1, с. 691]. Согласно Словарю В. И. Даля, глагол «прожухнуть» применяется для характеристики свежести масляной краски и используется в значении 'зажухнуть, потемнеть, стать мутным, испортиться'. Таким образом, в контексте новообразование означает 'темно-серый цвет, возникший на поверхности мебели под воздействием времени'.

Цвет интерьера комнаты описан при помощи окказионального прилагательного «серо-белявый» (ср.: «серо-синявый»). Слово функционирует в нетипичном сочетании серо-белявая невзрачность (ком- 
наты) [7, с. 555], так как в общем языке слово «белявый» служит для характеристики 'блондина, человека светловолосого, обладающего светло-русыми волосами' [9]. В контексте новообразование называет светло-серый цвет.

Суффикс -acm-, характерный для прилагательных, производных от имен существительных, называющих внешний интенсивный признак человека, зафиксирован в новообразовании «седастый» (седой $\rightarrow$ седастый). В эпизоде, в котором Мандро подвергает пыткам профессора Коробкина, стремясь завладеть математическим открытием, автор дает описание нечеловеческого облика Мандро, который предстает то разъяренной гориллой, то существом, кидающимся на Ивана Ивановича «седастыми рогами». Окказиональное сочетание «седастые роги» может выражать разную степень проявления признака, в зависимости от варианта значения суффикса -acm-: 1) рога, обладающие интенсивным внешним признаком, т. е. рога серые, цвета седины; 2) рога, цвет которых похож на цвет седины, сероватые [7, с. 354]. Ср. также «новодранцы седявые» [Там же, с. 434]. Суффикс -яв- в окказионализме «седявый» используется для передачи как интенсивности, так и неполноты, частичного проявления признака. В основе окказионализма «новодранцы» лежит каламбурный способ словообразования. Буквенная контаминация позволяет установить связь между словом «новобранцы» и просторечным словом с оттенком презрительности «голодранцы».

Окказиональное прилагательное «серебропёрый» (о сугробе) образовано при помощи сложения основ с нулевой суффиксацией: И серебропёрой загривиной переострился сугроб [7, с. 536]. Новообразование «серебропёрый» служит для характеристики референта по цвету и форме - сугроб цвета серебра, блестяще белый, по форме напоминающий перья. Новообразование «загривина», выделенное в Словаре В. Даля со значением 'задняя часть шеи, подзатыльник, завоек. Нижняя часть самой гривы, у холки; загривок нередко висит особым клочком' [9, т. 1, c. 536], используется для характеристики части тела животного или человека [Там же]. В контексте окказиональное существительное употреблено в составе необычной синтагмы; сугроб сравнивается с удлиненным, заостренным пером на задней части шеи у птицы.

При помощи новообразования «сребродрогий», образованного сложением основ слов «серебро» и «дрожать» с нулевой суффиксацией, описаны кусты, которые «дрожат серебром» после дождя, стоят в серебряных каплях.

Окказиональное существительное «серебреи», производное от слова «серебро» с присоединением суффикса -ей-, номинирует хлопья снега: Серебреи зареяли: засеребреили [7, с. 587]. Однокоренной окказиональный глагол «засеребреить» в контексте означает 'начать сверкать, заблистать'. Восприятие созданной картины усиливается звукописью и корневым повтором.

При изображении зимнего пейзажа Андрей Белый в пределах одного предложения объединяет окказиональные слова: Серебрянцем заляпало солнце на блещенский снег [7, с. 642]. Существительное «серебрянец» в контексте служит для наименования лучей света, которые солнце «грубо, аляповато бросило» на снег. Окказиональное прилагательное «блещенский», называющее блестящий, сверкающий на солнце снег, образовано при помощи суффикса -енск- с нарушением типичной сочетаемости данного форманта и основы блесте-.

Для обозначения сверкающих снежных масс автор создает окказиональное существительное «серебернь». Наблюдается эпентеза, расширение производящей основы слова «серебро» неморфемным компонентом «е». Новообразование с суффиксом -нь употребляется в контексте: Сереберни струят по стене, по забору [7, с. 603].

Для изображения вечернего и дневного сияния льда на реке писатель сополагает ряд окказиональных существительных, различных по семантике цвета: Вечером там - золотарни, блисталища; и хризолитовая серебрень там - в полудень [7, с. 645]. В тексте романа покрытая льдом поверхность реки в вечернее время описывается А. Белым как 'имеющая золотой, блестяще-желтый цвет, будто позолоченная’. Окказиональное существительное «блисталище», мотивированное глаголом «блистать», в контексте служит для характеристики зеркальной глади замерзшей реки, отражающей яркий свет закатного солнца.

В середине дня данный пейзаж напоминает «хризолитовую серебрень»; поверхность льда отражает «зеленоватое, небесное сияние» [7, с. 645]. Окказиональное существительное «серебрень», образованное при помощи суффикса -ень-, употреблено в сочетании с качественным прилагательным «хризолитовый» в значении 'зелено-желтый оттенок, подобный по цвету прозрачному драгоценному камню хризолиту’. В контексте словосочетание передает зелено-желтое сияние прозрачной поверхности льда.

\section{Выводы}

Представленные в статье окказиональные наименования белого цвета служат для характеристики персонажей, предметов быта, элементов архитектурных строений, представителей городской флоры и фауны, а также главных отличительных свойств описываемого пространства. При помощи новообразований, содержащих сему 'серебряный', А. Белый 
создает детали зимнего пейзажа, автор описывает хлопья и сугробы снега, их свечение и форму. Окказиональные наименования серого цвета и его оттенков в романе служат для характеристики предметов быта, подвергшихся с течением времени гниению и распаду.

В группе окказиональных ахроматических цветов преобладают традиционные для общего языка прилагательные. Особенностью идиостиля Андрея Белого является употребление композитов, уточняющих цветовой оттенок. В поэтическом языке Андрея Белого сложные прилагательные, называющие цвет, обладают особой экспрессивностью и наиболее ярко демонстрируют те ассоциативные поля, которые становятся решающими для писателя при выборе формы репрезентации замысла. Основой для многих композитных прилагательных является сравнение, отражающее уникальное мировосприятие писателя-символиста. Часть цветообозначений создана окказиональными абстрактными существительными, обозначающими пространство с признаком цвета.

Прокомментированные в статье окказиональные прилагательные образованы морфологическим способом: словообразующим средством являются суффикс -яв-, реже -енск- и -acm-, а также сложение основ с суффиксацией.

Отдельные новообразования были рассмотрены в синтагме параллельно с грамматическими окказионализмами. Выделена группа семантических новообразований, источником которых стали словарные статьи из «Толкового словаря живого великорусского языка» В. И. Даля.

\section{ЛИТЕРАТУРА}

1. Кожевникова Н. А. Словообразовательные гнезда в романе А. Белого «Москва» // Текст. Интертекст. Культура : сб. докл. Междунар. конф. (Москва, 4-7 апреля 2001 г.). М. : Азбуковник, 2001. С. 520-533.

2. Горелкина A. В. Словообразовательные окказионализмы в мемуарных прозаических произведениях М. Цветаевой и А. Белого : автореф. дис. ... канд. филол. наук. М., 1999. 21 c.

3. Кошелева C. В. Новообразования в идиолекте Андрея Белого (на материале романов «Петербург» и «Москва») : автореф. дис. ... канд. филол. наук. Орел, 2003. 19 c.

4. Петров А. В., Сова Ю. Словообразовательная структура и семантика окказионализмов, называющих части тела человека (на материале романа А. Белого «Москва») // Ученые записки Крым. Федер. ун-та им. В. И. Вернадского. Филологические науки. 2020. Т. 6 (72), № 4. С. 150-164.
5. Фрумкина Р. М. Цвет, смысл, сходство. Аспекты психолингвистического анализа : монография. М. : Наука, 1984. 175 с.

6. Бельй $A$. Символизм как миропонимание. М. : Республика, 1994. 528 с.

7. Бельй А. Москва / сост., вступ. ст. и примеч. С. И. Тиминой. М. : Сов. Россия, 1989. 768 с.

8. Ушаков Д. Н. Толковый словарь русского языка. М. : Сов. энцикл. ; ОГИЗ ; Гос. изд-во иностр. и нац. слов., 1935-1940.

9. Даль В. И. Толковый словарь живого великорусского языка : в 4 т. М. : ТЕРPА, 1995.

\section{REFERENCES}

1. Kozhevnikova N. A. Slovoobrazovatelnye gnezda $\mathrm{v}$ romane A. Belogo Moskva [Word-Building Nests in A. Belyi's Novel Moscow]. In: Tekst. Intertekst. Kul'tura: sbornik dokladov Mezhdunarodnoi konferentsii (Moskva, 4-7 aprelya 2001 g.). Moscow: Azbukovnik, 2001. Pp. 520533.

2. Gorelkina A. B. Slovoobrazovatelnye okkazionalizmy $\mathrm{v}$ memuarnykh prozaicheskikh proizvedeniyakh $\mathrm{M}$. Tsvetaevoi i A. Belogo: avtoref. dis. ... kand. filol. nauk [Word-building occasionalisms in the memoir prose by M. Tsvetaeva and A. Belyi. Abstract of thesis]. Moscow, 1999. $21 \mathrm{p}$.

3. Kosheleva S. V. Novoobrazovaniya v idiolekte Andreja Belogo (na materiale romanov Peterburg i Moskva): avtoref. dis. ... kand. filol. nauk [Neologisms in the idiolect of Andrei Belyi (based on the novels Petersburg and Moscow). Abstract of Thesis]. Available at: https://www. dissercat.com/content/novoobrazovaniya-v-idiolekteandreya-belogo-na-materiale-romanov-peterburg-i-moskva

4. Petrov A. V., Sova J. Slovoobrazovatel'naja struktura i semantika okkazionalizmov, nazyvajushhih chasti tela cheloveka (na materiale romana A. Belogo «Moskva») In: Uchjonye zapiski Krymskogo federal'nogo universiteta imeni V. I. Vernadskogo. Filologicheskie nauki. 2020. T. 6 (72), No. 4. Pp. 150-164.

5. Frumkina R. M. Cvet, smysl, shodstvo. Aspekty psiholingvisticheskogo analiza : monografija. Moscow: Nauka, 1984. 175 p.

6. Belyj A. Simvolizm kak miroponimanie. Moscow : Respublika, 1994. 528 p.

7. Belyi A. Moskva [Moscow]. Comp and intr. by S. I. Timina. Moscow: Sovetskaya Rossiya Publ., 1989. 768 p.

8. Ushakov D. N. Tolkovyj slovar' russkogo jazyka. Moscow : Sov. jencikl.; OGIZ; Gos. izd-vo inostr. i nac. slov., 1935-1940.

9. Dal V. I. Tolkovyi slovar zhivogo velikorusskogo yazyka: $\mathrm{v}$ 4-kh Tomakh [Explanatory dictionary of the living great Russian language. In 4 Volumes]. Moscow : TERRA Publ., 1995. 
Крымский федеральный университет имени В. И. Вернадского

Петров А. В., доктор филологических наук, профессор кафедры русского, славянского и общего языкознания

E-mail: liza_nada@mail.ru

Сова Ю. А., магистрант

E-mail: sovayulia8@gmail.com

Поступила в редакциюю 15 мая 2021 г.

Принята к публикаџии 15 июня 20212.

\section{Для иитирования:}

Петров А. В., Сова Ю. А. Окказиональные обозначения ахроматических цветов в романе А. Белого «Москва» // Вестник Воронежского государственного университета. Серия: Лингвистика и межкультурная коммуникация. 2021. № 3. C. 115-121. DOI: https://doi. org/10.17308/lic.2021.3/3588
Crimean Federal University named after V. I. Vernadsky Petrov A. V., Doctor of Philology, Professor of the Russian, Slavic and General Linguistics Department

E-mail: liza_nada@mail.ru

Sova Yu. A., Master-Student

E-mail: sovayulia8@gmail.com

Received: 15 May 2021

Accepted: 15 June 2021

\section{For citation:}

Petrov A. V., Sova Yu. A. Occasional nominations of achromatic colours in the roman by A. Bely "Moscow". Proceedings of Voronezh State University. Series: Linguistics and Intercultural Communication. 2021. No. 3. Pp. 115-121. DOI: https://doi.org/10.17308/lic.2021.3/3588 